\title{
A Study On Factors That Influence Consumers' Decision Process Towards Sustainable Products in A Retail Store Environment
}

\author{
Sarwin Kumar ${ }^{1}$, Tripti Singh ${ }^{2}$ \\ Department of Design, Indian Institute of Information Technology Design and Manufacturing Jabalpur, Madhya Pradesh
} 482005, India

\begin{abstract}
The study aims to assess the market gap between Indian consumers and brand managers in a retail store. India is one of the countries where awareness about carbon footprint per capita is very low and hence people often do not choose the eco-friendly brands over the polluting brands. For this reason, brands and brand managers also give very little importance to Sustainable Development Goals (SDGs) set by United Nations Development Programme. One of the places an individual can reduce their carbon footprint is by choosing sustainable brands over others. Consumers are often unaware of how environmentally damaging their favourite brand's products are unless it is brought up in the media and on social platforms. At the same time, they also have very little information about environmentally friendly brands; therefore, sales of sustainable, socially responsible products and services do not reflect the efforts invested in their development. The results of this study show the factors that influence the consumer decision-making process towards sustainable brands/products and the importance of the change in consumer behaviour.
\end{abstract}

Keywords: Sustainable consumption, Mindful consumers, Carbon footprint, Consumer behaviour 


\section{Introduction}

India has seen a tremendous growth in the number of companies focusing on sustainability in the last few years. This seems to be a right step in the age of environmental decay. Globally, climate change, environmental degradation and the alarming growth of garbage islands in the oceans are constant fodder for the news cycles. Consumers have become aware of how their daily purchasing decisions negatively impact the natural world. This increased awareness has led to a significant shift in consumer behaviour towards sustainable products and sustainable retail. Indian consumer's purchasing habits have changed over the years, they associate brand's sustainability and ethical practices with "trust on the brand" - a key driver for brand preference [1].

For years, brand managers have groused that, while consumers say they intend to buy sustainable products, in store they don't actually purchase them [2]. This conventional wisdom has been used by many brands as justification for not making their products more sustainable [2]. Sales of sustainable, socially responsible products and services do not reflect the effort invested in their development.

This research focuses on understanding the gap between consumer and brand manager understanding of sustainable brands and the decision making process in a retail store. Interviews and surveys were conducted and users were interviewed to understand their mental model and the issues they face in retail. Preliminary research found that the paucity of information on product packaging and the large number of greenwashing brands made consumers question their purchasing decisions. This is one of the unaddressed issues that sustainable brands fail to address and thus fail to capture the attention of their target audience and achieve the market position they deserve.

\section{Literature survey}

Consumer buyer behaviour is considered to be an inseparable part of marketing and Kotler and Keller (2011) state that consumer buying behaviour is the study of the ways of buying and disposing of goods, services, ideas or experiences by the individuals, groups and organizations in order to satisfy their needs and wants [3]. Buyer behaviour has been defined as "a process, which through inputs and their use though process and actions leads to satisfaction of needs and wants" [4]. Consumer buying behaviour includes numerous factors that are believed to have some influence on customers' buying decisions. In a survey conducted by A.T. Kearney in April 2019, suggests a sizeable year on year jump in the percentage of consumers, who are changing their purchasing behaviour in favour of products with sustainable traits. The results of the survey of participants from 7 different countries (UK, France, Japan, USA, Germany, India and China) revealed that $72 \%$ of the Indian respondents are actively looking for brands that are sustainable and trustworthy. 
Another survey conducted by A.T. Kearney with 1000 participants on March 2019, March 2020 and April 2020 (post Covid) as show in the figure 1 to understand the shift in behaviour over the year and impact of Covid in the sustainable products consumption behaviour of consumers [5].

\begin{tabular}{|l}
\hline Kearney Earth Day \\
Consumer \\
Sentiments Survey \\
Survey Question: \\
Do you consider \\
environmental impacts when \\
making a purchase decision?
\end{tabular}

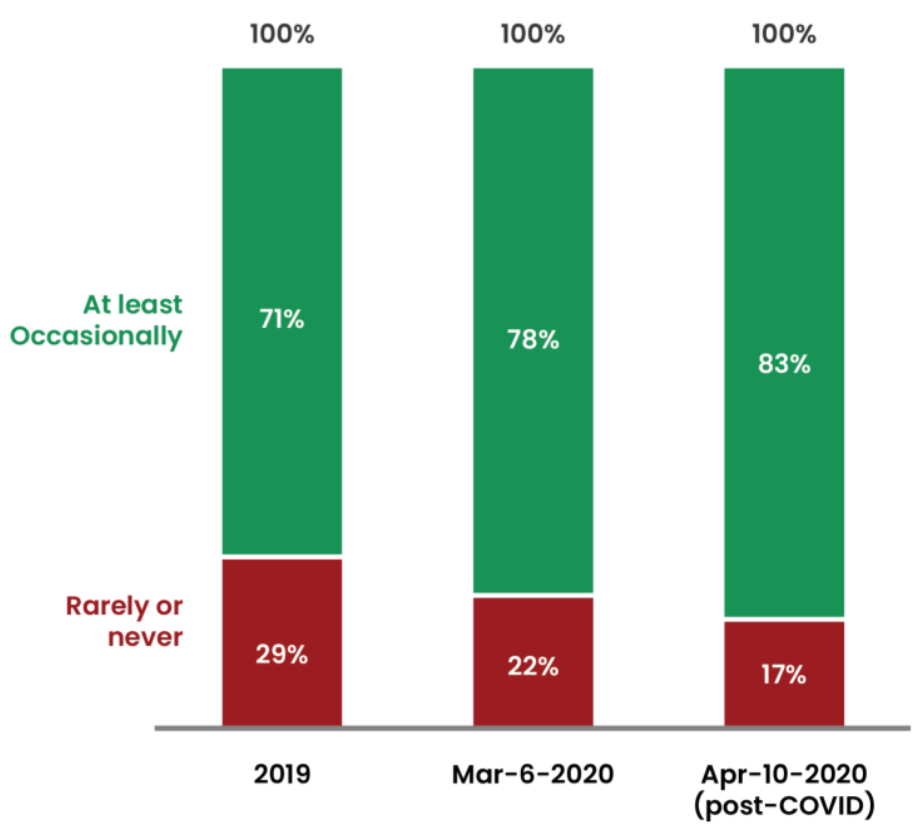

Figure 1: Kearney Earth Day Consumer Sentiments Survey

This shift demonstrates that retailers must immediately develop capabilities to meet this shift in buying behaviour. Retailers that ignore this trend are likely to miss a significant opportunity to tap into a new, growing, "green" consumer base.

\subsection{Shift in consumer demographics}

A generation is a group of people born around the same time and raised around the same place. People in this "birth cohort" exhibit similar characteristics, preferences, and values over their lifetimes. There are big differences between the generations and it's important to know the years when each generation begins and ends. [6]. Currently, five generations make up our society and each of these five generations has an active role in the marketplace.

Depending on the specific job, the workforce includes four to five generations.

Here are the birth years for each generation:

- Gen Z, iGen, or Centennials: Born 1997 - 2016 
- Millennials or Gen Y: Born 1981 - 1997

- Generation X: Born 1965 - 1980

- Baby Boomers: Born 1946 - 1964

- Traditionalists or Silent Generation: Born 1928 - 1945

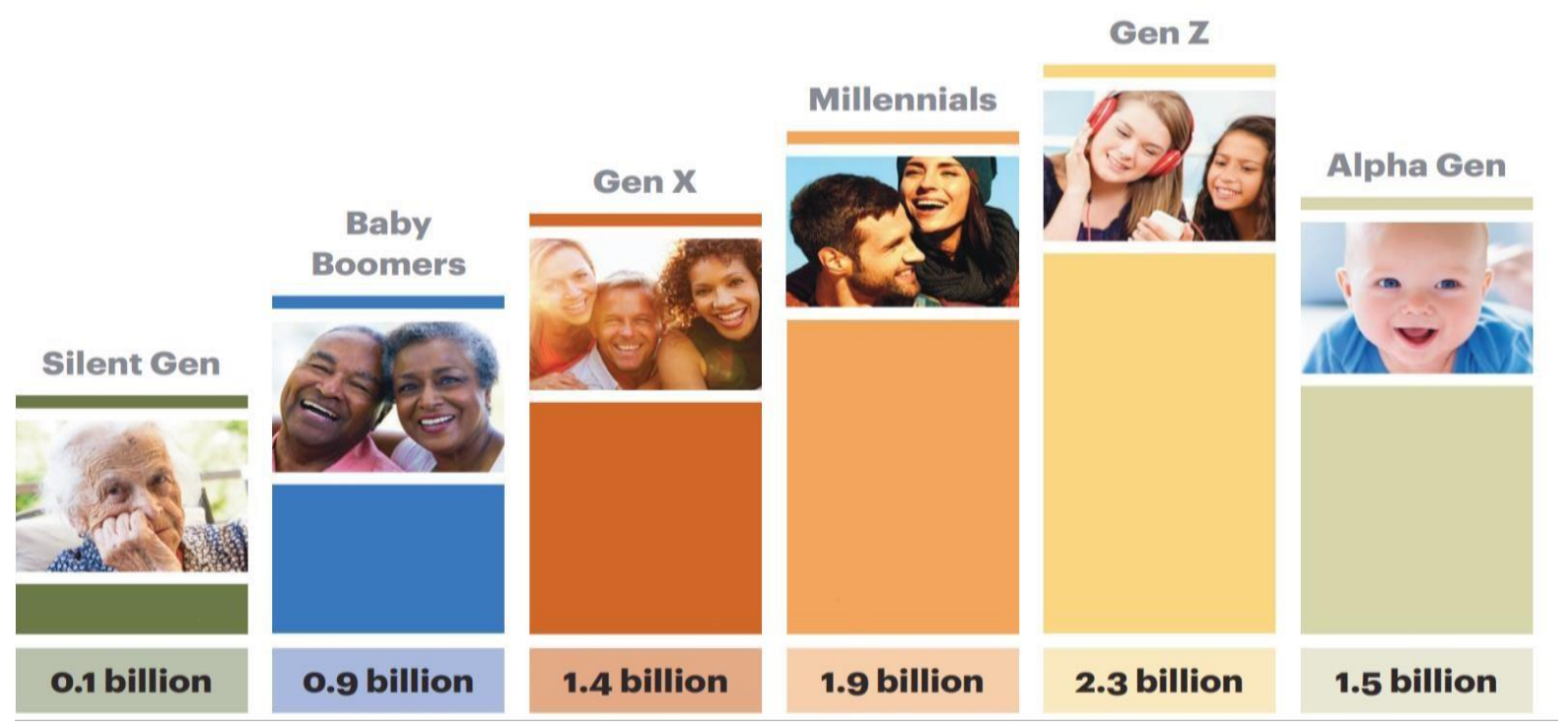

Figure 2: Different generations in market by 2027 [A.T. Kearney analysis]

By 2027, there will be six different generations of consumers in the market, as shown in Figure 2. The Silent Generation and the so-called Alpha Generation (2017-TBD) - will have limited purchasing influence in 2027. The remaining 4 generations will have a high commercial influence: Baby Boomers, Gen X, Millennials \& GenZ [7].

\subsection{Greenwashing}

TerraChoice defines greenwashing as "the act of misleading consumers regarding the environmental practices of a company or the environmental performance and positive communication about environmental performance". Greenwashing was first accused in 1986 by activist Jay Westered, when hotels begin asking guests to reuse towels, claiming that it was a company water conservation strategy, although, did not have any environmental impact [8]. Although greenwashing has been around for many years, its use has escalated sharply in recent years as companies strive to meet rising consumer demand for greener products and services, according to advertising consultancy TerraChoice Environmental Marketing.

TerraChoice in its report in 2009, identifying 2,219 products making green claims - an increase of $79 \%$ over the company's first report two years earlier. TerraChoice also concluded that $98 \%$ of those products were guilty of greenwashing [9]. 
When companies greenwash, they not only reduce sustainable practices to a mere symbol, but they also mislead consumers. "The common denominator of among all greenwashing is that it is not only misleading, but it's also really not helping to further sustainable design or circular economy initiatives. Thus, environmental problems stay the same or more likely, get even worse, as greenwashing often sucks up airtime and misdirects well-intentioned consumers down the wrong path." [Leyla Acaroglu]

\section{Methodology}

The research methodology is a way to collect relevant data from the various stakeholders in the focal ecosystem in order to gain a clear understanding of the real issues they face. As part of this process, several field visits were conducted to small retail stores and supermarkets in Chennai to conduct surveys and interviews with various stakeholders in their natural environment. A two-part, 12-item survey instrument was developed to explore participants' beliefs about sustainable products and their perceptions of sustainable brands. The survey was largely based on questions about sustainable products and practises and included questions that used a fivepoint Likert scale (high likely being 5 to less likely being 1). A draft survey was trialled and was revised based on the feedback.

\subsection{Survey and focus groups}

The survey was conducted with 20 participants through an online platform to gain a broad understanding of the various factors that influence a customer's consumption in a retail store. The categories of questions focused on a) participants' consumption and perceptions of sustainable products and sustainable brands, and b) factors that potentially influence their decision-making process. Survey data was collected via an online platform and paperpencil method, with only one response per participant recorded. After data collection, the participant data were analysed using spreadsheets based on the responses to the different items. After the survey responses and method of analysis, all findings from the surveys were analysed and evaluated. As a follow- up, focus group interviews were conducted to gain a deeper understanding of the influence of sustainability consumption in a retail store.

Focus group participants were randomly selected from the 20 survey participants. They were further interviewed and engaged with the card sorting method to prioritise the factors that influence their decision making process in a retail store. Participants were asked a series of open-ended questions about sustainability and its impact on their current lives. A closed card sorting method was used and participants were asked to sort the 5 factors in order of influence. Participants were continually questioned and asked to explain their decisionmaking process during the card sorting process to gain a deeper understanding of user choice. 


\section{Results and discussion}

As described in the methodology, surveys and focus groups were used to explore consumer attitudes and behaviors toward sustainable products. The results of the two-part survey, as shown in Figure 3 and Figure 4, are analyzed in the following sections.

\subsection{Survey}

The first part of the survey focused on the participants' consumption and perception towards sustainable products and sustainable brands. $70 \%$ of the participants have bought sustainable products before and $90 \%$ of the participants show great interest in buying products with the sustainability label. In contrast, $40 \%$ of the participants buy products with the sustainability label once a month, $10 \%$ of the participants buy sustainable products less than once a month and the Whereas the remaining 50\% are not aware of their consumption of sustainable products. A large majority of the participants (90\%) showed their willingness to buy sustainable products when more of these options are available and $100 \%$ of the participants believe that there is a difference between conventional products and products with the sustainability label. This clearly shows that awareness and willingness to purchase branded sustainable products is high among consumers and is in line with A.T. Kearney's April 2019 survey results. The results from the first part of the survey show that participants are actively looking to purchase branded sustainable products.

The second part of the survey focuses on factors that potentially influence consumers' decisionmaking process regarding sustainable products. The responses on the five-point Likert scale show that 5 represents strongly agree and 1 represents strongly disagree. The results show that the participants have a strong distrust on the credibility of the existing eco-labels in the market and this distrust is due to the lack of transparency in the whole production process of these products and their certification claims. Shelf availability (shelf space is the amount of space allocated to a particular product by a wholesaler or retailer) also plays an important role in the selection of a product as they believe that the constant availability of the product is important to switch and also recommend it to others as well. 


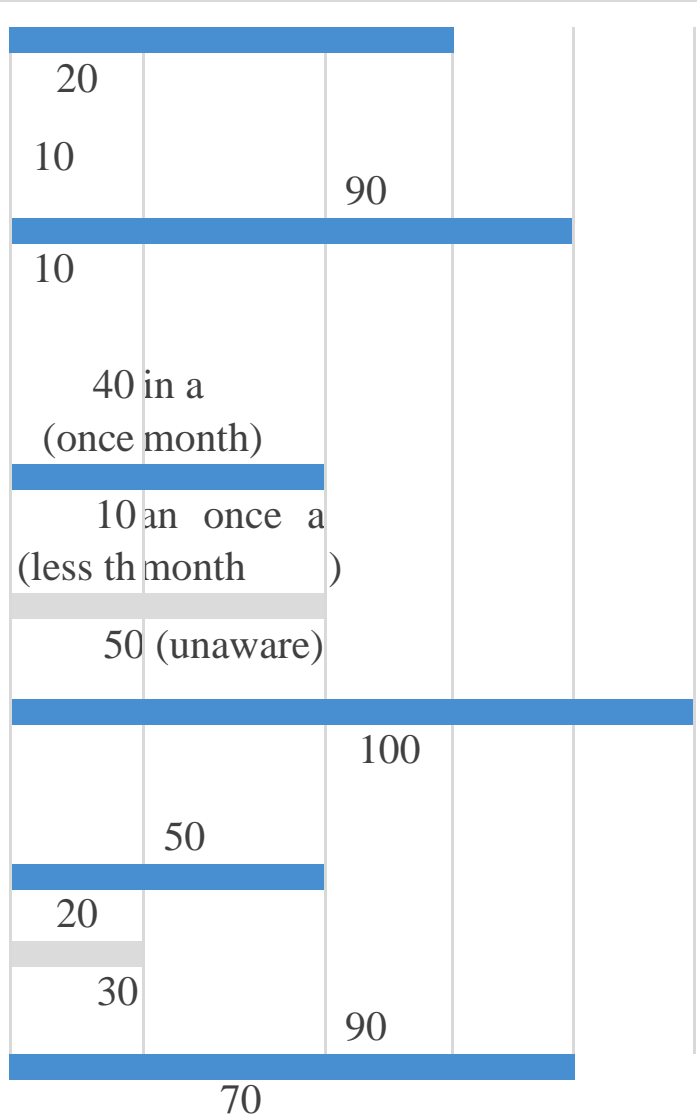

Have you ever bought a product branded "sustainable"?

Do you have an interest of buying sustainablelabelled products?

How often are you buying sustainable-labelled products?

Do you think that there is any difference between conventional products and sustainable-labelled products?

Do you feel any deficiency of sustainablelabelled products in the stores?

If there were more sustainable-labelled product options would 
4th International Conference on Modern Research in SOCIAL SCIENCES

you buy more of these products?

Yes No I don't know

Figure 3: Results of Part one survey

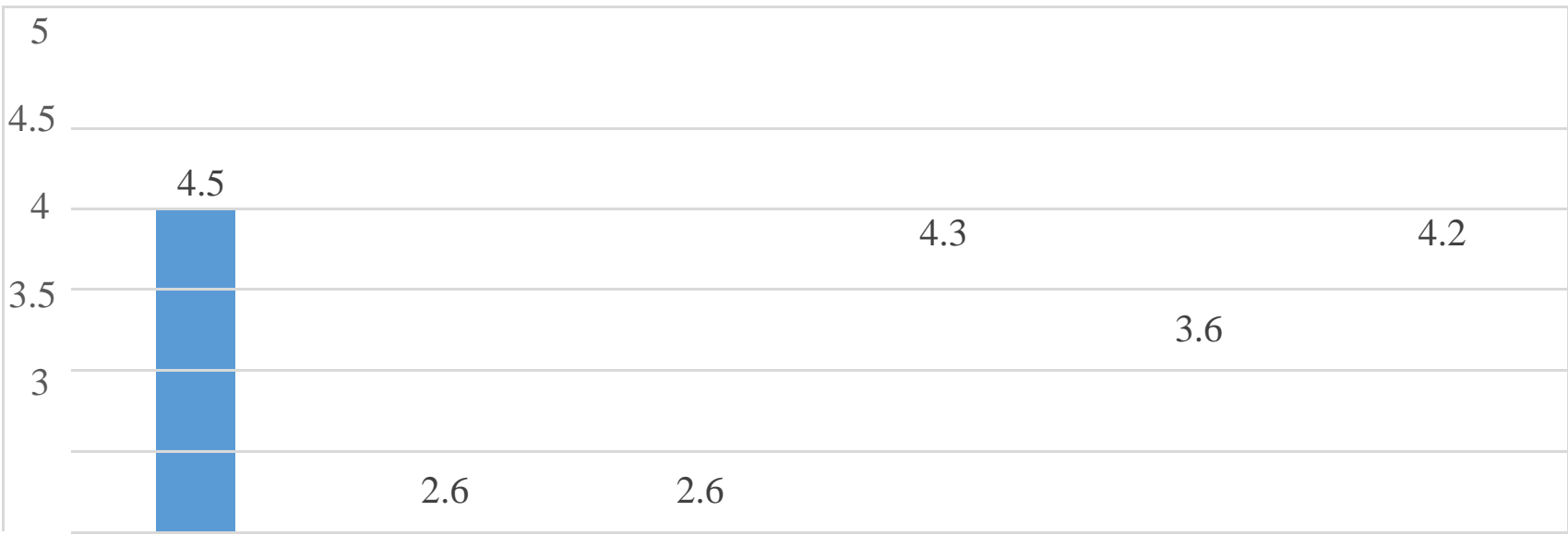


4th International Conference on Modern Research in SOCIAL SCIENCES

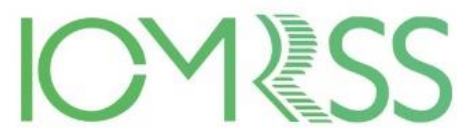

29-31 July, 2021

MUNICH, GERMANY

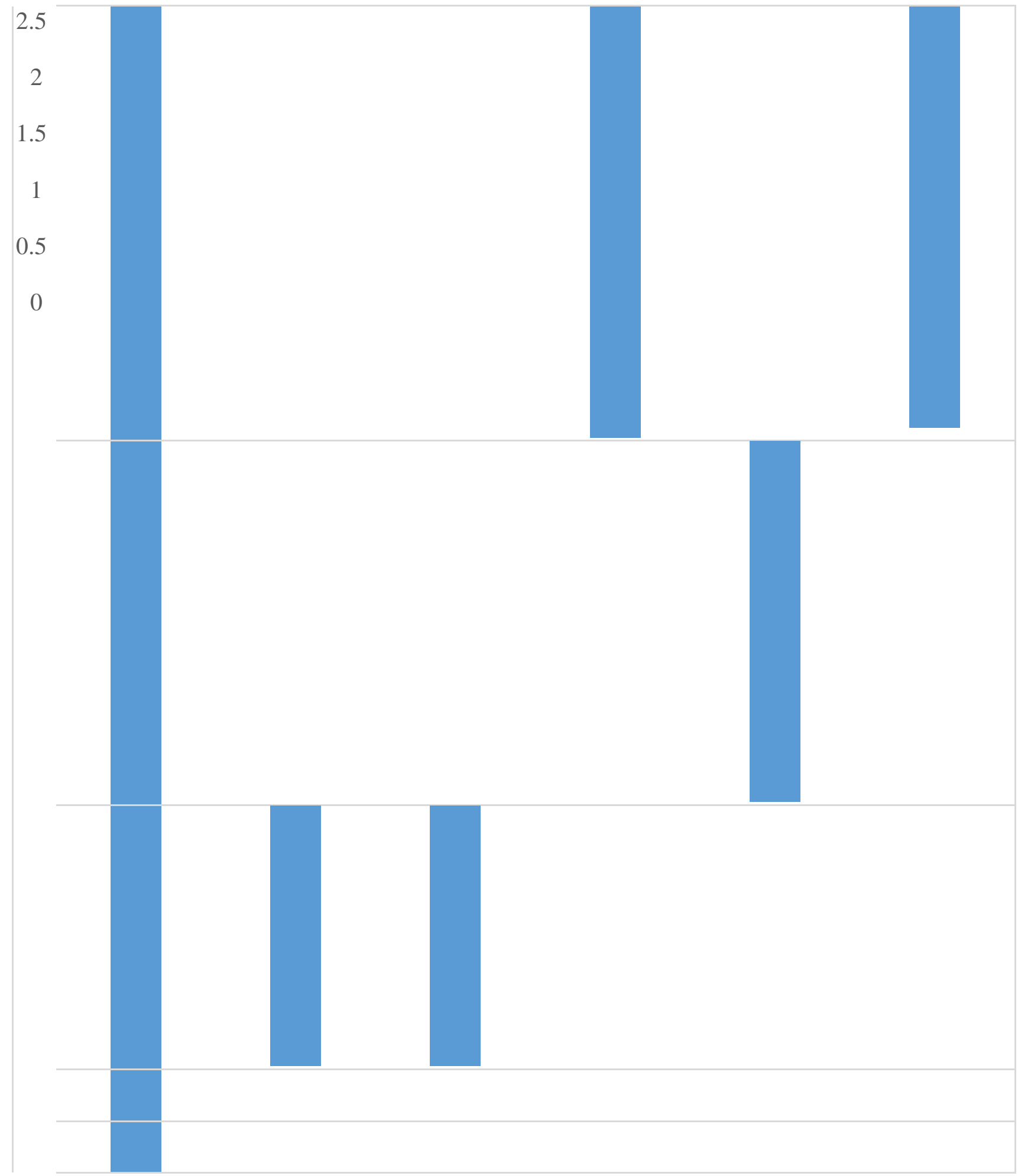




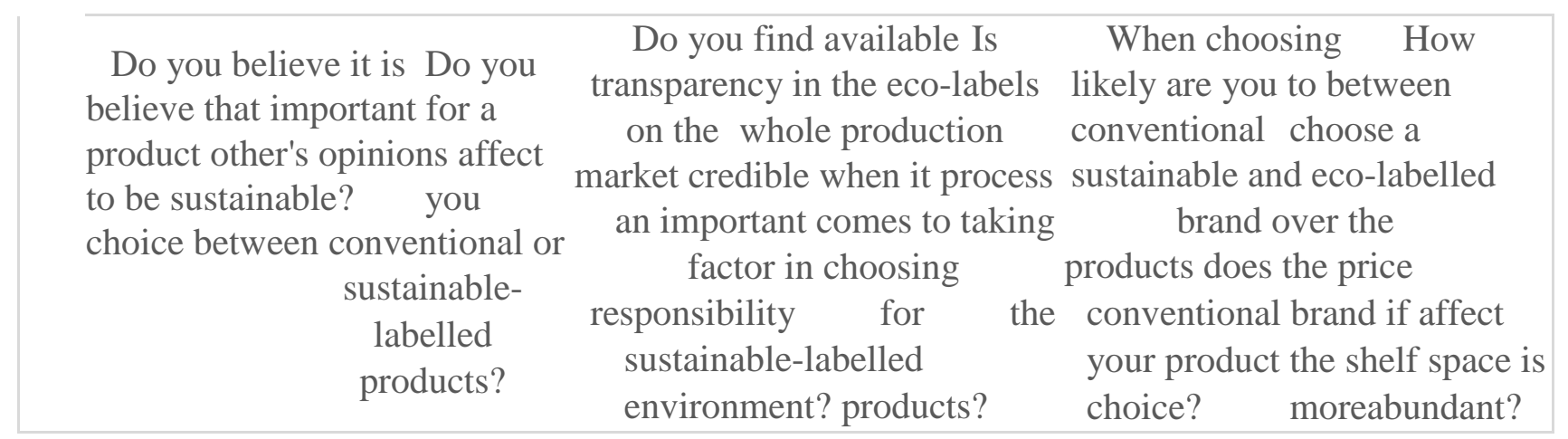

Figure 4: Results of Part two survey

\subsubsection{Summary}

- Though majority of people seem to have interest in buying sustainable products, very few buy them and often buy very less products only.

- People only have a vague understanding about sustainability and sustainable products.

- The labels available on the products in the market are less credible and trustworthy.

- The shelf space available for a product in stores play a major role in choosing one brand over the another.

- People believe there is deficiency in the number of sustainable product options and they are often difficult to identify.

\subsection{Focus groups}

Focus group participants' responses focused on two themes: the importance of understanding an individual's carbon footprint and how they can influence others in this process.

\subsubsection{Pyramid of influence towards sustainable consumption}

The one-to-one closed card sorting method and the in-depth interviews with the focus group participants resulted in the following findings and the creation of the sustainable consumption influence pyramid, as shown in Figure 5. The following findings were obtained after the interview

- Sustainability knowledge is considered the most important factor among the 5, as people believe that sustainability knowledge makes a consumer feel guilty for choosing harmful brands over others.

- Sustainability motivation is followed by sustainability knowledge since motivation cannot be developed without even having the knowledge about the existence in the first place.

- Following sustainability knowledge is the peer influence. A personal recommendation from a fellow consumer or a friend/family member plays a vital role is trying new 
brands, as they find them more credible than brand managers and marketing labels/posters.

- The price of a product does not play a crucial role in one-time purchase decisions, but it does in regular purchase decisions. Price can be neglected if it is marginal and proves to be more valuable than competitors.

- Shelf space in stores also plays an important role in choosing one brand over another as consumers buy what they see the most.

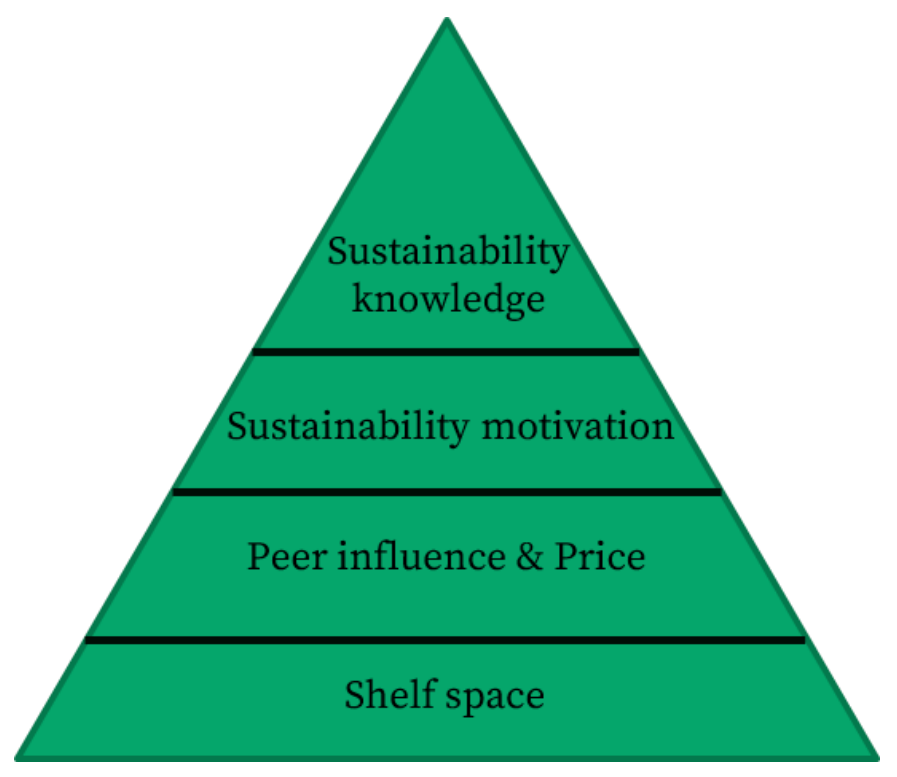

Figure 5: Pyramid of influence towards sustainability consumption

\subsubsection{The importance of understanding carbon footprint as an individual}

The plethora of conversation with focus group clearly indicated that, participants recognized the importance of individual's carbon footprint and influence of daily choices towards climate change. As Stuti, on of the focus group participant stated, "I am responsible for my actions and the carbon emissions I produce, I wish everyone would think like me and make an effort to carbon emissions". The sustainability awareness needs to be more than just the understanding of numbers, the information on carbon footprint should tap with the emotions to ensure actions. Another participant Selva noted: "my academic exposure to carbon footprint per capita opened my eyes wider when making any purchase choices nowadays. I started to hunt for brands which make fake claims towards sustainability and joined many forums of like-minded people". The participants also reveal that, "lack of constant motivation to stay on the sustainability plank is difficult as an individual and we often feel lonely in the sustainability way of living". Ultimately, participants concurred that understanding of carbon footprint helps to take actions either in the form of guilt or in the form of moral obligation. 


\subsubsection{The influence model}

The growth of social media channels over the years has promoted micro-influencers (thousands of followers, strong personal influence in their community) over the macro-influencers (celebrities with millions of followers) as they seem to engage more effectively and connect with their followers to build trust. A focus group participant quoted that, "the days when people used to purchase products just by television ads are long gone. local Vloggers (video bloggers) provide honest reviews and have major influence towards purchase decision choices". Many tech companies have already started to leverage the micro-influencers to promote and build a mutual beneficial relationship. The influence model is much stronger with the younger generation of consumers, as they actively engage with the micro-influencers more than the other generation.

Participants also pointed out the importance of communicating with others about the actions they are taking. Swetha noted, "Every time I post something proactive towards sustainability way of living, I often have a meaningful conversation with others and help others take action. The conversations about carbon footprints, climate degradation are usually had in the big halls of universities. It needs to happen on the streets, at tea stalls and in casual conversations with friends/colleagues to have a real impact on the global climate crisis." The focus group responses suggest that micro influence plays a greater role in creating awareness and motivation for appropriate lifestyles than the macro method of approach.

\section{Conclusion}

As the consumer market demographics is going to change over the next decade, it is important for brands to understand the shift in consumer behaviour towards consumer products. The results show the various factors and their influence towards sustainable brand decision process in a retail store environment. Insights reveal that brands need to adopt to upcoming trends and change their approach of influence towards consumers for a better reach and growth. The above research concludes that sustainable brands need to develop more of a transparent approach in their products certifications, labels and their manufacturing process to gain the trust of the consumer and make the decision process effortless. 


\section{References}

1. Debashish Mukherjee, Subhendu Roy, Manoj Muthu Kumar; CII India Retail Summit 2019: Building towards sustainable retail

2. Tensie Whelan, Randi Kronthal-Sacco; "Actually, Consumers Do Buy Sustainable Products (2019)" https://hbr.org/2019/06/research-actually-consumers-do-buysustainable-products

3. Kotler.P and Keller.K (2011) Marketing Management (Vol. 14th edition). London Pearson Education. Consumer Buyer Behaviour Definition - Research Methodology

4. Enis, B.M. (1974) "Marketing Principles: The Management Process" Consumer Buyer Behaviour Definition - Research Methodology

5. Greg Portell, Corey Chafin, Christina Carlson; "Kearney Earth day sentiments survey (2019 \& 2020)"

6. Generational birth years; The centre for Generational Kinetics, Austin, Texas 78757 USA https://genhq.com/FAQ-info-about-generations/

7. Mirko Warschun, Natalie Shield, Imran Dassu; “A.T. Kearney Global Future Consumer study" A.T.Kearney global Future Consumer Study

8. TerraChoice (2010) The sins of greenwashing: home and family edition. http://sinsofgreenwashing.org/findings/the-seven-sins/.

9. TerraChoice Environmental Marketing The Seven Sins of Greenwashing: Environmental Claims in Consumer MarketsLondonTerraChoice Environmental Marketing2009. Available:

http://sinsofgreenwashing.org/findings/greenwashing-report-2009/

10. Leyla Acaroglu; "What is Greenwashing? How to Spot It and Stop it" 